\title{
Endoscopic diagnosis of an MRI-occult, low-grade glioma with ependymal dissemination
}

\author{
Konstantinos Margetis, MD, PhD, ${ }^{1}$ Prajwal Rajappa, MD, ${ }^{1}$ William Cope, BS, ${ }^{2}$ David Pisapia, MD, ${ }^{3}$ \\ and Mark M. Souweidane, MD'
}

Departments of ${ }^{1}$ Neurosurgery and ${ }^{3}$ Pathology and Laboratory Medicine, Weill Cornell Medical College, NewYork-Presbyterian Hospital; and ${ }^{2}$ Weill Cornell Medical College, New York, New York

\begin{abstract}
A 21-year-old man presented with triventricular hydrocephalus due to a tectal mass. He underwent an endoscopic third ventriculostomy, and multiple nodules were identified at the floor of the third ventricle intraoperatively. Surgical pathology of one of these lesions demonstrated that the tissue represented a low-grade astrocytoma. The case highlights the existing potential of neuroendoscopy to reveal neuroimaging-occult lesions, in spite of the significant advances of MRI. Furthermore, the combination of the age of the patient, the nonenhancing MRI appearance, and the multifocality of the lesions constitutes a rare and interesting neoplastic presentation within the brain. The constellation of findings likely represents dissemination of a low-grade tectal glioma via the CSF compartment.

http://thejns.org/doi/abs/10.3171/2015.3.PEDS14444
\end{abstract}

KEY WORDS neuroendoscopy; glioma; astrocytoma; cerebrospinal fluid; third ventricle; neoplasm metastasis; oncology

$\mathrm{M}$ AGNETIC resonance imaging has proved to be the imaging modality of choice for the evaluation of intraventricular brain tumors, which have an extensive differential diagnosis. ${ }^{35}$ However, MRI of the brain often needs to be supplemented with spinal MRI and CSF cytological assessment to provide a complete evaluation of metastatic potential. ${ }^{35}$

Tectal gliomas are a group of intraventricular tumors defined primarily by their location. Most often, they are low-grade astrocytomas and are considered indolent tumors that can be effectively managed in most cases with CSF diversion surgery and serial neuroimaging alone. ${ }^{34}$ Their propensity to progress, let alone metastasize, is considered negligible, particularly for those histologically diagnosed as low-grade astrocytomas. Endoscopic third ventriculostomy (ETV) is a preferred method for the treatment of obstructive hydrocephalus for this disease. Herein, we present the case of a lesion that was initially considered to be a typical tectal glioma, but at the time of neuroendoscopy, intraventricular dissemination was recognized.

\section{Case Report}

Presentation

A 21-year-old man presented with a 7-year history of headaches. Initially, his headaches were thought to be migrainous, but they progressed in frequency and intensity. Right-sided tinnitus and facial paresthesias ultimately led to brain MRI that revealed a $10 \times 11 \times 14-\mathrm{mm}$ mass projecting inferiorly from the midbrain tectum (Figs. 1-3). The mass was slightly $\mathrm{T} 2$ hyperintense and $\mathrm{T} 1$ hypointense with no definite enhancement. There was marked dilation of the third and lateral ventricles with mild periventricular white matter T2 hyperintensity, consistent with transependymal flow of CSF. The radiological findings were thought to be most consistent with a tectal glioma. Sagittal T1weighted, axial T1-weighted, axial T2-weighted FLAIR, and thin-section sagittal 3D CUBE (GE Healthcare) MRI sequences were obtained. Axial and coronal reformats were also constructed from the CUBE data. Neurological examination revealed left lateral nystagmus, but findings

ABBREVIATION ETV = endoscopic third ventriculostomy.

SUBMITTED September 10, 2015. ACCEPTED March 18, 2015

INCLUDE WHEN CITING Published online July 3, 2015; DOI: 10.3171/2015.3.PEDS14444.

DISCLOSURE The authors report no conflict of interest concerning the materials or methods used in this study or the findings specified in this paper. Dr. Souweidane is a paid consultant to the Aesculap Advisory Council. 


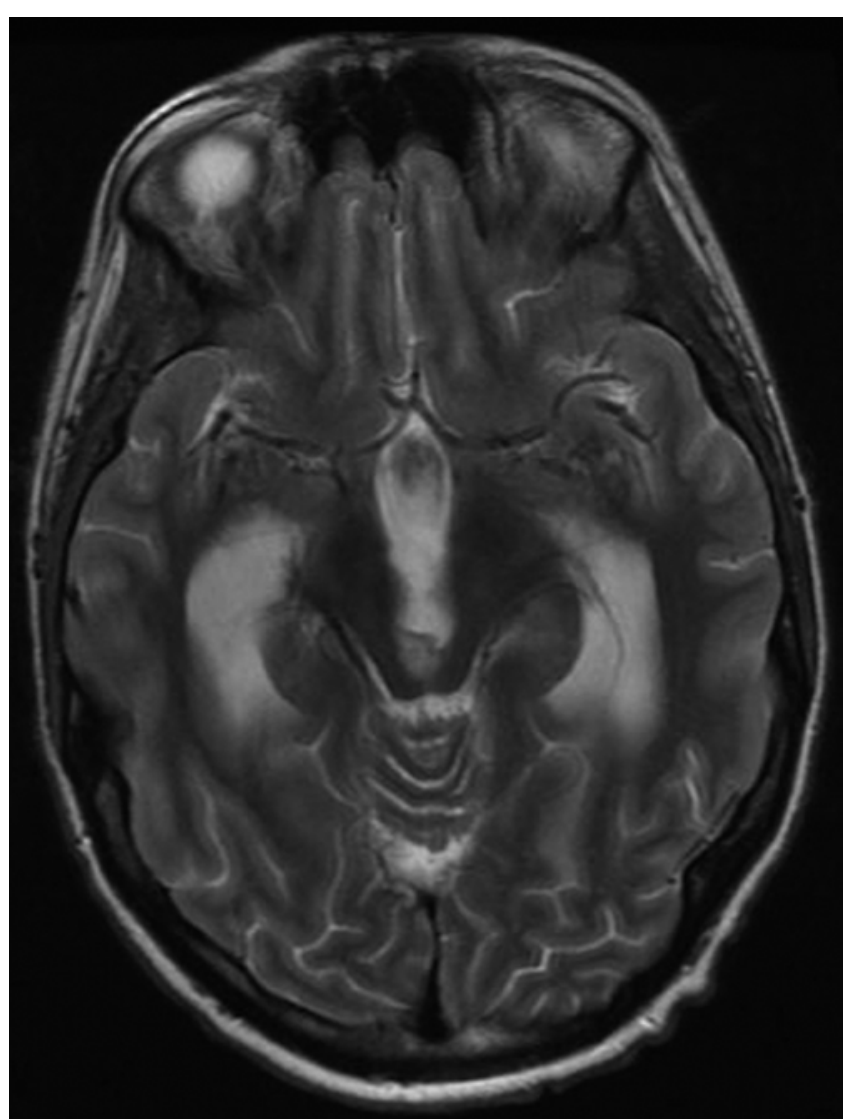

FIG. 1. Preoperative axial T2-weighted MR image showing the hyperintense tectal mass.

were otherwise unremarkable. Given the finding of triventricular, noncommunicating hydrocephalus secondary to a mesencephalic mass with imaging characteristics of a tectal glioma, an ETV was planned.

\section{Operation}

On initial ventriculoscopic observation, a number of nodules were visualized to be attached on the ependymal surface of the third ventricle (Video 1).

VIDEO 1. Video showing the initial inspection of the third ventricle and recognition of the abnormal nodules, the performance of the ETV, the biopsy of a prominent nodule, and the inspection of the subarachnoid space through the stoma site. Copyright Mark M. Souweidane. Published with permission. Click here to view with Media Player. Click here to view with Quicktime.

Morphologically, these were consistent with neoplastic lesions, and, given their multiplicity, most likely appeared to represent metastases (Fig. 4). The ETV was then performed utilizing a blunt biopsy forceps, just at the posterior aspect of the dorsum sellae. The tuber cinereum and the membrane of Liliequist were opened. Then, the largest lesion was biopsied and sent for histological diagnosis (Fig. 5). The ETV stoma was then gradually dilated utilizing a 3-F embolectomy catheter. Clear visualization of the prepontine subarachnoid space through the stoma site indicated no evidence of metastatic seeding.

Postoperative brain MRI did not show any complications. However, some abnormalities in the fourth ventricle and in the right lateral ventricle were considered to be ad-

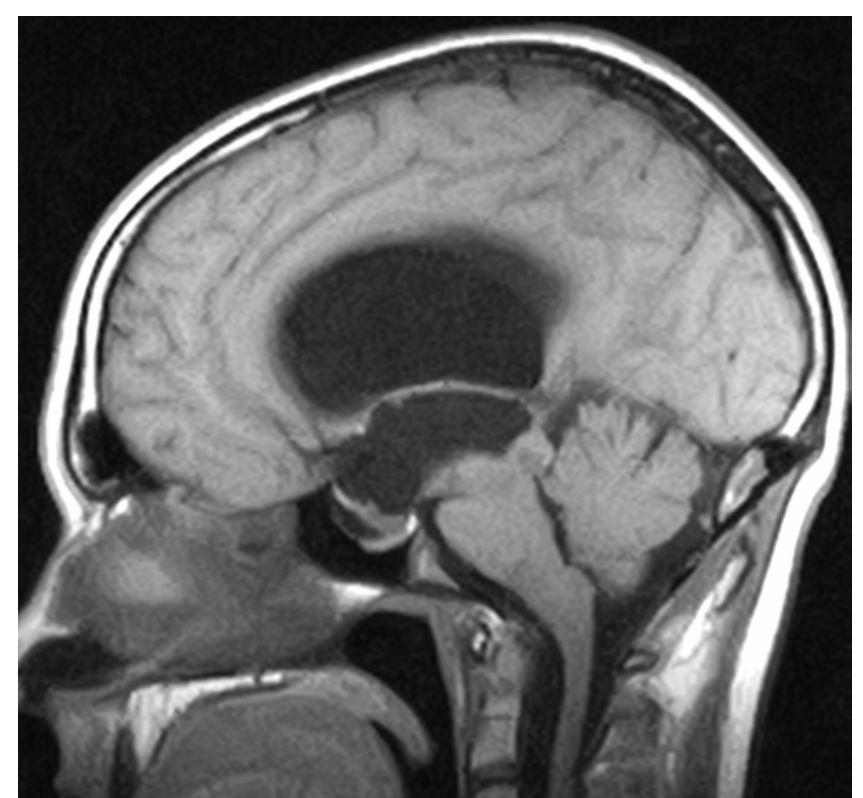

FIG. 2. Preoperative sagittal T1-weighted MR image showing the slightly hypointense tectal mass.

ditional lesions. A spine MRI searching for metastatic disease was negative.

\section{Pathology}

The neuropathologist's diagnosis was diffuse astrocytoma (WHO Grade II). More specifically, the pathology report stated that the tumor consisted of mildly pleomorphic neoplastic glial cells with subependymal spread of neoplastic cells (Fig. 6a and b). The immunohistochemical profile of the neoplastic cells showed positive staining for GFAP (Fig. 6c), focal positivity for P53, a Ki 67 proliferation index of $<1 \%$ (Fig. 6d), and negative staining for mutated BRAF (V600E), IDH1 (R132H), synaptophysin, and NeuN.

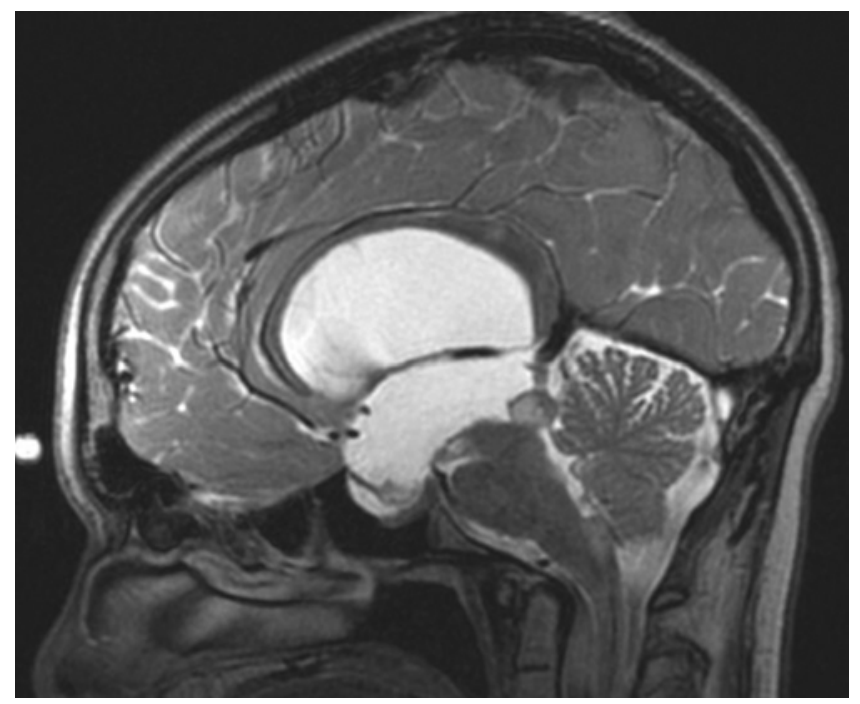

FIG. 3. Preoperative sagittal T2-weighted MR image. The third ventricular floor does not have any clear pathological abnormality. 


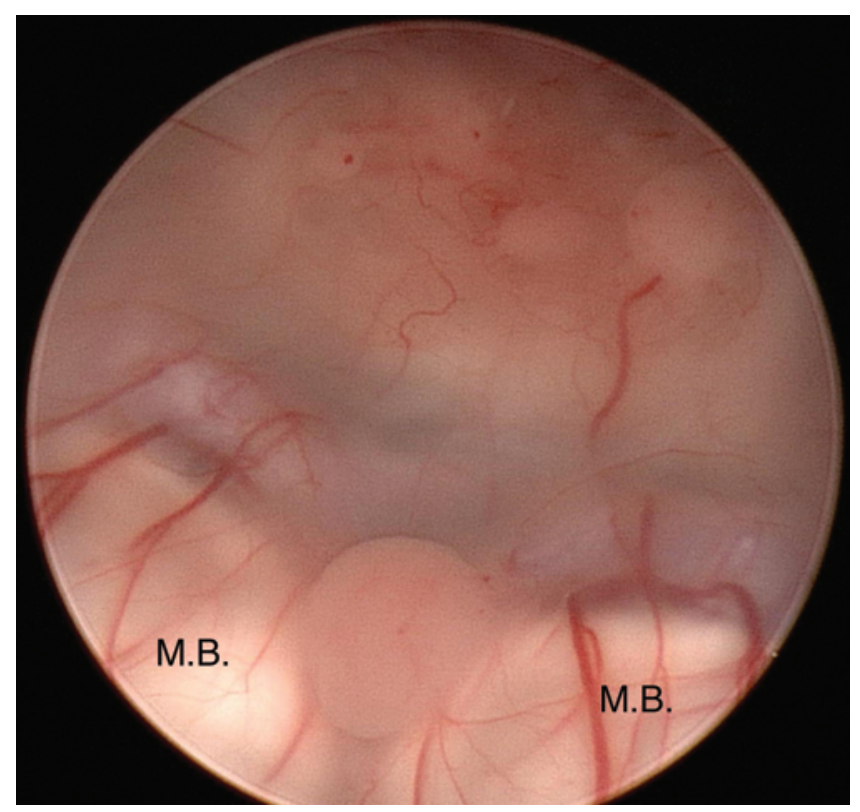

FIG. 4. Intraoperative image showing the abnormal nodules at the floor of the third ventricle. The most prominent nodule is located between the mammillary bodies (M.B.).

\section{Postoperative Course}

The patient was asymptomatic on follow-up, and MRI performed 4 months postoperatively did not show any changes in the lesion. The subcentimeter lesions along the dorsal aspect of the pons and medulla, as well as the ependymal floor of the right occipital horn, were also stable.

Nine months postoperatively, the patient remained asymptomatic; he had graduated from college and was pursuing the career of his choice. The MRI study at this point showed no appreciable change in the presumed tectal glioma. There was a low likelihood of a subtle increase in the size of the nonenhancing FLAIR/T2 signal abnormality along the floor of the right occipital horn, while the other multiple nonenhancing FLAIR/T2 signal abnormalities were unchanged in size. Repeat spine MRI failed to detect any metastases. The patient continues to undergo follow-up with serial MRI, according to the recommendations of the multidisciplinary pediatric tumor board.

\section{Discussion}

The direct visualization afforded by neuroendoscopy was introduced in 1910, when Victor Darwin Lespinasse performed the first endoscopic procedure, which was a choroid plexus cauterization..$^{12}$ Despite the current impressive advance of neuroimaging modalities, the direct visualization allowed by neuroendoscopy has been shown to reveal, on rare occurrence, pathology that does not appear on neuroimaging. We acknowledge that this is not the only example in which neuroendoscopy reveals pathology that is MRI occult. Germinomas of the third ventricular wall have been diagnosed with neuroendoscopy in the absence of MRI findings, suggesting that neuroendoscopy might be more sensitive than MRI in the detection of small intraventricular lesions. ${ }^{28,36}$ Both of these cases raise the possibility of using endoscopy as an added measure of meta-

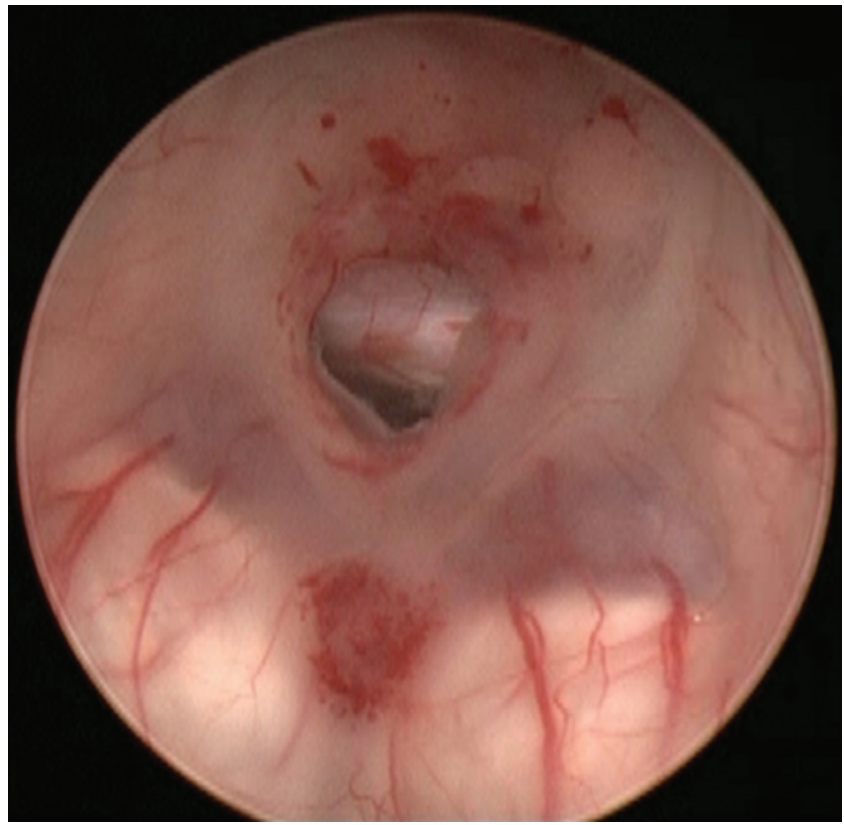

FIG. 5. Intraoperative image showing the biopsy and ETV sites.

static potential. There is an increasing use of simultaneous endoscopic tumor biopsy of pineal region tumors. ${ }^{23}$ At a minimum, we believe it may be of importance that a relative comment be made in operative records of all patients with intraventricular tumors if endoscopy is performed.

The metastatic potential of high-grade gliomas is well documented, $1,3,4,6,7,10,13,14,19-21,24,25,30-32$ even to extraneural locations. ${ }^{11}$ The metastatic potential of pilocytic astrocytomas $^{5,9,18}$ and oligoastrocytomas ${ }^{16,33}$ has also been described. Metastasis by a low-grade, nonpilocytic astrocytoma has been rarely reported in the literature, although the first report was in $1930 .{ }^{29} \mathrm{~A}$ literature review yielded 18 cases of metastatic, low-grade gliomas that were not juvenile pilocytic astrocytoma (Table 1). The majority refer to pediatric patients, but 5 cases were observed in adult patients. ${ }^{15,17,27,29}$ Notably, in the sole case in which MRI appearance of a satellite lesion is reported, the metastasis was enhancing, unlike those seen in our case. ${ }^{17}$

The pathological process presented in this case could theoretically represent multiple, synchronous primary astrocytomas. However, the degree of multiplicity in conjunction with the exclusive intraventricular ependymal localization of these lesions renders this possibility less likely than a scenario in which these lesions represent seeding through the CSF. In this latter scenario, however, the fact that the metastases are localized to the ventricular system and are not seen within the spine or the intracranial subarachnoid space raises the question of how CSF seeding becomes regionally restricted. The impairment of normal CSF flow as a consequence of the patient's noncommunicating hydrocephalus may play a role. An additional factor may be related to subtle differences in tumor microenvironment that permit growth of tumorlets in some areas of the CNS but not others. The limited nature of the specimen that was sent for histological analysis precluded more definitive exclusion of a higher grade component within the tumor. Nevertheless, given the degree of gross similar- 

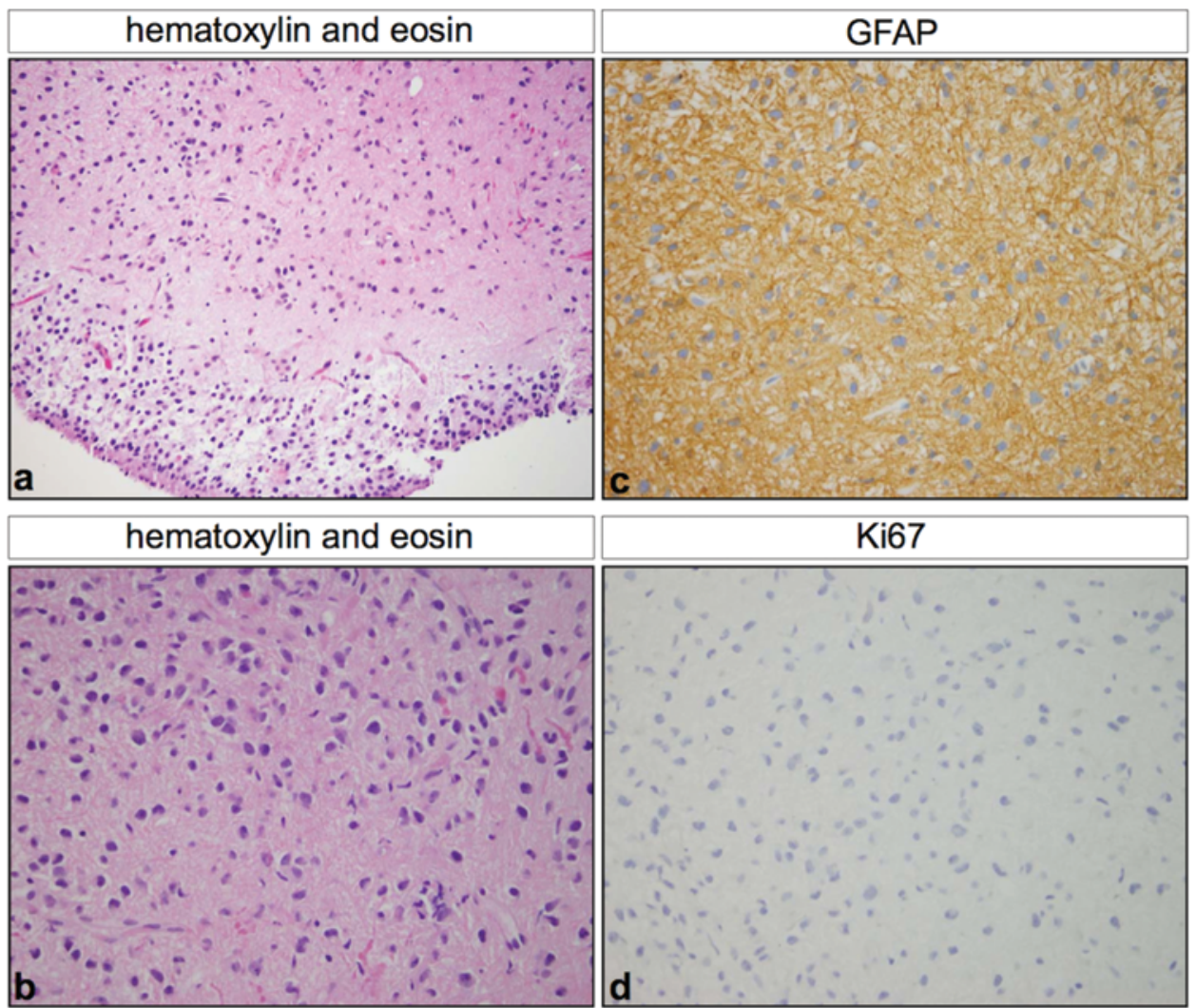

FIG. 6. Morphological and immunohistochemical features of the low-grade astrocytic neoplasm. a: The neoplasm is astrocytic in morphology and exhibits subependymal spread of tumor cells. b: Cellular atypia and occasional Rosenthal fibers are appreciated. c: The tumor cells are strongly positive for glial fibrillary acidic protein. d: The Ki 67 proliferation is less than 1\%. Original magnification $\times 200(a) ; \times 400(b-d)$.

TABLE 1. Literature review of CSF seeding cases from low-grade, non-juvenile pilocytic astrocytoma, gliomas

\begin{tabular}{|c|c|c|c|c|}
\hline Authors \& Year & $\begin{array}{l}\text { Age at Diagnosis of } \\
\text { Metastasis (yrs), Sex }\end{array}$ & Pathology & $\begin{array}{l}\text { Site of Primary } \\
\text { Tumor }\end{array}$ & Site of Metastasis \\
\hline Russell \& Cairns, 1930 & $28, \mathrm{M}$ & Fibrillary astrocytoma & Thalamus & Spinal cord \\
\hline \multirow{3}{*}{$\begin{array}{l}\text { Polmeteer \& Kernohan, } \\
1947\end{array}$} & 18, not stated & Fibrillary astrocytoma & Midbrain & Widespread \\
\hline & 15, not stated & Protoplasmic astrocytoma & Corpus callosum & Widespread \\
\hline & 32 , not stated & Protoplasmic astrocytoma & 3rd ventricle & Widespread \\
\hline \multirow[t]{3}{*}{ Civitello et al., 1988} & 3 , not stated & Fibrillary astrocytoma & Cervical cord & $\begin{array}{l}\text { Basal cisterns, tentorium, chiasm, hypothalamus, } \\
\text { spinal cord }\end{array}$ \\
\hline & 3.5 , not stated & Fibrillary astrocytoma & Cervical cord & Basal cisterns, tentorium \\
\hline & 6 , not stated & Fibrillary astrocytoma & Cervical cord & Cerebral white matter, vermis, spinal cord \\
\hline Pollack et al., 1994 & $7, \mathrm{M}$ & Microcystic astrocytoma & 4th ventricle & Basal cisterns \& supratentorial ventricular system \\
\hline \multirow[t]{5}{*}{ Gajjar et al., 1995} & $5 / 12, M$ & Astrocytoma & Hypothalamus & Spinal cord, ventricle, cerebellum \\
\hline & $5, M$ & Astrocytoma & Hypothalamus & Spinal cord, ventricle, cerebellum \\
\hline & $5, \mathrm{~F}$ & Astrocytoma & Spinal cord & Cerebral hemisphere, cerebellum \\
\hline & $13, \mathrm{M}$ & Astrocytoma & Spinal cord & Cerebral hemisphere, spinal cord, cerebellum \\
\hline & $20, \mathrm{~F}$ & Astrocytoma & Pons & Cerebral hemisphere, spinal cord \\
\hline Akar et al., 2000 & $8, M$ & Astrocytoma & Suprasellar & Basal cisterns, sacral spinal canal \\
\hline \multirow[t]{3}{*}{ Hukin et al., 2002} & 2.9, not stated & Fibrillary astrocytoma & Diencephalon & Spine \\
\hline & 15.8, not stated & Fibrillary astrocytoma & Diencephalon & Intracranial \& spinal cord \\
\hline & 22.8, not stated & Fibrillary astrocytoma & Brainstem & $\begin{array}{l}\text { Intracranial \& spinal cord (all lesions were enhancing } \\
\text { on MRI) }\end{array}$ \\
\hline Moon et al., 2012 & $16, M$ & Fibrillary astrocytoma & Pons & $\begin{array}{l}\text { Left cerebellopontine angle, leptomeningeal disease } \\
\text { of entire spine }\end{array}$ \\
\hline
\end{tabular}


ity between the sampled lesion and those left behind as well as the absence of enhancing lesions on imaging, it is probable that the histology seen in the sampled lesion is representative of the entirety of the multifocal process. Moreover, the stability of the remaining intraventricular lesions during follow-up also suggests that they are low grade in nature. While further genetic and molecular studies could not be conducted on the limited tissue and would have been interesting from a research perspective, it is unlikely that they would have been clinically significant, in terms of changing the management of the patient at this stage.

\section{Conclusions}

This case suggests that low-grade tectal astrocytomas may rarely have the potential for metastasis through the CSF pathways. More importantly, the current case highlights that direct visualization by neuroendoscopy remains relevant, even in the current era of advanced neuroimaging. It was the neuroendoscopy procedure that enabled us to visualize and diagnose the small ependymal lesions that eluded MRI diagnosis.

\section{References}

1. Aichholzer M, Mazal PR, Haberler C, Dietrich W, Bertalanffy A, Roessler K, et al: Epidural metastasis of a glioblastoma after stereotactic biopsy: case report. Minim Invasive Neurosurg 44:175-177, 2001

2. Akar Z, Tanriover N, Kafadar AM, Gazioglu N, Oz B, Kuday C: Chiasmatic low-grade glioma presenting with sacral intradural spinal metastasis. Childs Nerv Syst 16:309-311, 2000

3. Andrews AA, Enriques L, Renaudin J, Tomiyasu U: Spinal intramedullary glioblastoma with intracranial seeding. Report of a case. Arch Neurol 35:244-245, 1978

4. Bae JS, Yang SH, Yoon WS, Kang SG, Hong YK, Jeun SS: The clinical features of spinal leptomeningeal dissemination from malignant gliomas. J Korean Neurosurg Soc 49:334338, 2011

5. Bian SX, McAleer MF, Vats TS, Mahajan A, Grosshans DR: Pilocytic astrocytoma with leptomeningeal dissemination. Childs Nerv Syst 29:441-450, 2013

6. Bouillot-Eimer S, Loiseau H, Vital A: Subcutaneous tumoral seeding from a glioblastoma following stereotactic biopsy: case report and review of the literature. Clin Neuropathol 24:247-251, 2005

7. Chida K, Konno H, Sahara M, Takase S: [Meningeal seeding of spinal cord glioblastoma multiforme without any signs of myelopathy.] Rinsho Shinkeigaku 35:1235-1240, 1995 (Jpn)

8. Civitello LA, Packer RJ, Rorke LB, Siegel K, Sutton LN, Schut L: Leptomeningeal dissemination of low-grade gliomas in childhood. Neurology 38:562-566, 1988

9. Crabtree KL, Arnold PM: Spinal seeding of a pilocytic astrocytoma in an adult, initially diagnosed 18 years previously. Pediatr Neurosurg 46:66-70, 2010

10. Czepko R, Kwinta B, Adamek D, Uhl H, Betlej M, Lopatka $\mathrm{P}$ : [Multiple cerebral glioma or tumor dissemination via CSF pathways? Case report.] Neurol Neurochir Pol 37:13071315, 2003 (Polish)

11. Declercq H, De Man R, Vanderperre H, De Praetere P, Wilms G: Peritoneal seeding of a cerebral malignant astrocytoma via a ventriculo-peritoneal shunt. J Belge Radiol 75:191-193, 1992

12. Decq P, Schroeder H, Fritsch M, Cappabianca P: A history of ventricular neuroendoscopy. World Neurosurg 79 (2 Suppl):S14.e1-S14.e6, 2012

13. Erlich SS, Davis RL: Spinal subarachnoid metastasis from primary intracranial glioblastoma multiforme. Cancer 42:2854-2864, 1978

14. Fakhrai N, Czech T, Diekmann K, Fazeny-Dörner B, Birner P, Hainfellner JA, et al: Glioblastoma with spinal seeding. Strahlenther Onkol 180:455-457, 2004

15. Gajjar A, Bhargava R, Jenkins JJ, Heideman R, Sanford RA, Langston JW, et al: Low-grade astrocytoma with neuraxis dissemination at diagnosis. J Neurosurg 83:67-71, 1995

16. Huang JG, Kavar B, Smith PD: Intradural extramedullary spinal spread of oligoastrocytoma. J Clin Neurosci 14:879882,2007

17. Hukin J, Siffert J, Velasquez L, Zagzag D, Allen J: Leptomeningeal dissemination in children with progressive low-grade neuroepithelial tumors. Neuro Oncol 4:253-260, 2002

18. Jamjoom AB, Jamjoom ZA, al-Rayess M: Intraventricular and leptomeningeal dissemination of a pilocytic cerebellar astrocytoma in a child with a ventriculoperitoneal shunt: case report. Br J Neurosurg 12:56-58, 1998

19. Kim JE, Kim CY, Kim DG, Jung HW: Implantation metastasis along the stereotactic biopsy tract in anaplastic astrocytoma: a case report. J Neurooncol 61:215-218, 2003

20. Lam CH, Cosgrove GR, Drislane FW, Sotrel A: Spinal leptomeningeal metastasis from cerebral glioblastoma. Appearance on magnetic resonance imaging. Surg Neurol 35:377-380, 1991

21. Maslehaty H, Cordovi S, Hefti M: Symptomatic spinal metastases of intracranial glioblastoma: clinical characteristics and pathomechanism relating to GFAP expression. J Neurooncol 101:329-333, 2011

22. Moon JH, Jung TY, Jung S, Jang WY: Leptomeningeal dissemination of a low-grade brainstem glioma without local recurrence. J Korean Neurosurg Soc 51:109-112, 2012

23. Morgenstern PF, Souweidane MM: Pineal region tumors: simultaneous endoscopic third ventriculostomy and tumor biopsy. World Neurosurg 79 (2 Suppl):S18.e19-S18.e13, 2013

24. Perrin RG, Bernstein M: Iatrogenic seeding of anaplastic astrocytoma following stereotactic biopsy. J Neurooncol 36:243-246, 1998

25. Pierallini A, Caramia F, Piattella MC, Pantano P, Santoro A, Di Stefano D, et al: Metastasis along the stereotactic biopsy trajectory in glioblastoma multiforme. Acta Neurochir (Wien) 141:1011-1012, 1999

26. Pollack IF, Hurtt M, Pang D, Albright AL: Dissemination of low grade intracranial astrocytomas in children. Cancer 73:2869-2878, 1994

27. Polmeteer FE, Kernohan JW: Meningeal gliomatosis; a study of 42 cases. Arch Neurol Psychiatry 57:593-616, 1947

28. Reddy AT, Wellons JC III, Allen JC, Fiveash JB, Abdullatif $\mathrm{H}$, Braune KW, et al: Refining the staging evaluation of pineal region germinoma using neuroendoscopy and the presence of preoperative diabetes insipidus. Neuro Oncol 6:127-133, 2004

29. Russell DS, Cairns H: Spinal metastases in a case of cerebral glioma of the type known as astrocytoma fibrillare. J Pathol Bacteriol 33:383-391, 1930

30. Sarabia M, Millán JM, Escudero L, Cabello A, Lobato RD: Intracranial seeding from an intramedullary malignant astrocytoma. Surg Neurol 26:573-576, 1986

31. Schwaninger M, Patt S, Henningsen P, Schmidt D: Spinal canal metastases: a late complication of glioblastoma. J Neurooncol 12:93-98, 1992

32. Scoccianti S, Detti B, Meattini I, Iannalfi A, Sardaro A, Leonulli BG, et al: Symptomatic leptomeningeal and intramedullary metastases from intracranial glioblastoma multiforme: a case report. Tumori 94:877-881, 2008 
33. Seidel BU, Plöger H, Dietz H, Popescu-Pretor R: [Spinal seeding metastasis of a WHO grade III oligo-astrocytoma.] Neurochirurgia (Stuttg) 36:207-212, 1993 (Ger)

34. Stark AM, Fritsch MJ, Claviez A, Dörner L, Mehdorn HM: Management of tectal glioma in childhood. Pediatr Neurol 33:33-38, 2005

35. Vandesteen L, Drier A, Galanaud D, Clarençon F, Leclercq $\mathrm{D}$, Karachi C, et al: Imaging findings of intraventricular and ependymal lesions. J Neuroradiol 40:229-244, 2013

36. Wellons JC III, Reddy AT, Tubbs RS, Abdullatif H, Oakes WJ, Blount JP, et al: Neuroendoscopic findings in patients with intracranial germinomas correlating with diabetes insipidus. J Neurosurg 100 (5 Suppl Pediatrics):430-436, 2004

\section{Author Contributions}

Conception and design: Souweidane, Margetis, Rajappa, Pisapia. Acquisition of data: Margetis, Pisapia. Analysis and interpretation of data: Margetis. Drafting the article: Margetis, Rajappa, Cope.
Critically revising the article: all authors. Reviewed submitted version of manuscript: all authors. Approved the final version of the manuscript on behalf of all authors: Souweidane. Study supervision: Margetis.

\section{Supplemental Information \\ Videos}

Video 1, Media Player. http://mfile.akamai.com/21490/wmv/ digitalwbc.download.akamai.com/21492/wm.digitalsource-naregional/peds14-444_video_1.asx.

Video 1, Quicktime. http://mfile.akamai.com/21488/mov/ digitalwbc.download.akamai.com/21492/qt.digitalsource-global/ peds14-444_video_1.mov.

\section{Correspondence}

Mark M. Souweidane, Department of Neurosurgery, Weill Cornell Medical College, NewYork-Presbyterian Hospital, 525 E. 68th St., Box 99, New York, NY 10065. email: mmsouwei@med. cornell.edu. 